\title{
Jurist-Diction
}

Volume 4 No. 5 September 202

\section{Perubahan Baseline Negara Kepulauan Akibat Perubahan Iklim dalam Hukum Internasional}

\author{
Shofy Suma Nisrina dan Enny Narwati \\ shofy.suma.nisrina-2016@fh.unair.ac.id \\ Universitas Airlangga
}

How to cite:
Shofy Suma Nisrina dan Enny
Narwati, 'Perubahan Baseline
Negara Kepulauan Akibat
Perubahan Iklim dalam Hukum
Internasional' (2021) Vol. 4 No.
5 Jurist-Diction.
Histori artikel:
Submit 19 Juli 2021 ;
Diterima 15 Agustus 2021 ;
Diterbitkan 1 September 2021.
DOI:
10.20473/jd.v4i5.29833
p-ISSN: 2721-8392
e-ISSN: $2655-8297$
cc)

\section{Abstract}

Climatechangeis anaturalphenomenon thatoccur throughacomplicated and an evolutionary process. The impact of such natural phenomena is expected to shift the state's baseline following the geographical condition, consequently, it will also change the maritime zone owned by the state. The Law of the Sea has not regulated such impacts of the shifting baselines caused by natural phenomena which indicates a legal vacuum on this matter. This legal research examines the regulations and its implications which can be the basis of an archipelagic state's shifting baselines coverage due to natural phenomena. States have the discretion to establish their coordinates point and geographical maps, moreover, based on the 1982 United Nations Convention on Law of the Sea (UNCLOS 1982), States are required to make official map deposits to the United Nations Secretary-General. The deposited baseline is permanent as long as the state does not make any updates.

Keywords: Baseline; Climate Change; Archipelagic States; Law of The Sea.

\begin{abstract}
Abstrak
Permukaan air laut yang meningkat menjadi salah satu akibat dari perubahan iklim. Fenomena meningkatnya permukaan air laut merupakan peristiwa alami yang terjadi secara evolusi sehingga proses terjadinya memerlukan jangka waktu yang lama. Dampak dari fenomena alam tersebut dapat mengakibatkan terjadinya pergeseran baseline negara mengikuti kondisi geografis yang terdampak sehingga terjadi perubahan wilayah negara atas laut. Hukum Laut belum mengatur mengenai kemungkinan terjadinya pergeseran baseline akibat fenomena alam ini sehingga merupakan suatu kekosongan hukum yang dapat menjadi potensi sengketa antar negara. Penelitian ini mengkaji atas dampak dan pengaturan yang dapat menjadi landasan apabila terjadi perubahan baseline negara terutama negara kepulauan seperti Indonesia yang sangat rentan akibat fenomena alam. Setiap Negara memiliki diskresi untuk menetapkan koordinat serta peta geografisnya mengingat kondisi wilayah yang berbedabeda, dan berdasarkan Konvensi Hukum Laut 1982 (UNCLOS 1982), negara wajib melakukan deposit peta resmi ke Sekretaris Jenderal PBB. Baseline yang telah didepositkan merupakan baseline yang tetap selama negara tidak melakukan pembaharuan.

Kata Kunci: Baseline; Perubahan Iklim; Negara Kepulauan; Hukum Laut. Copyright $(\underset{2}{2021}$ Shofy Suma Nisrina dan Enny Narwati
\end{abstract}




\section{Pendahuluan}

Perubahan iklim merupakan hal yang menjadi kecemasan masyarakat baik nasional maupun internasional, mengingat dampak-dampaknya terlihat secara nyata seperti meningkatnya suhu bumi dan laut, serta mencairnya bukit es. ${ }^{1}$ Belakangan ini, isu perubahan iklim menjadi isu yang menarik untuk dibahas sebagaimana semakin banyak kejadian yang ekstrim seperti data berdasarkan National Oceanic and Atmospheric Administration's National Centers for Environmental Information ${ }^{2}$ bahwa tahun 2019 merupakan tahun yang menginjak suhu terpanas dalam pencatatan sejak 140 tahun yang lalu, ${ }^{3}$ selain itu para ilmuwan telah menyatakan dan membuktikan bahwa mencairnya pegunungan es yang ada di Greenland dan Antartika terjadi secara signifikan ${ }^{4}$ dengan rata-rata kenaikan permukaan air laut sebanyak 2,74 mm per tahunnya di beberapa negara. ${ }^{5}$ Kenaikan permukaan air laut tersebut akan berdampak merugikan dan mengancam negara-negara yang memiliki kepulauan seperti di Maldives dan Kepulauan Marshall, ${ }^{6}$ Negara-negara yang paling terpengaruh oleh peristiwa kenaikan air laut akibat perubahan iklim antara lain negara-negara kepulauan dan coral atoll yang hanya berjarak tiga meter dari

\footnotetext{
${ }^{1}$ Anny Cazenave, 'Global sea-level budget 1993-present' (2018) 10 Earth Syst. Sci. Data, [1551-1590].

${ }^{2}$ National Oceanic and Atmospheric Administration's (NOAA) National Centers for Environmental Information adalah agensi sejak tahun 1970 yang berlokasi di Amerika Serikat dan fokus pada kondisi laut, saluran air besar dan atmosfer. Kegiatan utama dari NOAA adalah untuk memonitor dan meninjau sistem bumi dengan data yang dikumpulkan melalui jaringan dunia, menilai dan memprediksi perubahan dari sistem bumi sepanjang waktu, melakukan hubungan dan menganjurkan serta menginformasikan kepada masyarakat umum dan rekan organisasi. Lihat: U.S. Department of Commerce, 'New Priorities for the 21 st Century: NOAA Strategic Plan FY 2005 - FY 2010.', (NOAA, 2004).[3], <http://oceanservice.noaa.gov/about/pdfs/noaa_strat_plan_2005_2010. pdf $>$, accessed 10 Desember 2019.

${ }^{3}$ Tara Law, 'Record-Breaking Temperatures Around the World Are 'Almost Entirely' Due to Climate Change' (Time, 2019) <https://time.com/5652972/july-2019-hottest-month/>, accessed 8 Oktober 2019.

${ }^{4}$ J. L. Chen, et.al. 'Satellite Gravity Measurements Confirm Accelerated Melting of Greenland Ice Sheet' (2006) 313 Science.[1958].

5 Agence-France Presse, 'Sea level rise from ocean warming underestimated, scientists say' (The Guardian, 2016) < https://www.theguardian.com/environment/2016/jan/26/sea-level-rise-from-ocean-warming-underestimated-scientists-say $>$ accessed 19 Agustus 2019.

${ }^{6}$ Pam Wright, 'Rising Seas Will Render Many Pacific Islands Uninhabitable by Mid-Century, Study Says' (The Weather Channel, 2018), dalam <https:/weather.com/science/environment/ news/2018-04-26-rising-seas-pacific-atoll-islands-uninhabitable-mid-century> accessed 19 Agustus 2019.
} 
permukaan air laut sekarang dan tidak memiliki dataran lebih tinggi yang dapat digunakan untuk relokasi, seperti Maldives, Marshall Islands, Tuvalu, Kiribati, dan Tokelau. Negara-negara tersebut memiliki resiko tinggi terdampak dengan tenggelamnya wilayah, erosi, dan banjir bandang akibat badai. Selain itu, terdapat jumlah air bersih yang sedikit, yang dapat semakin berkurang akibat masuknya air laut. ${ }^{7}$ Tak hanya itu, perubahan cuaca ekstrem juga mengancam keberlangsungan hidup hewan dan tanaman asli negara-negara kepulauan kecil tersebut, sehingga menyangkut isu serius dari segi hukum lingkungan internasional pula. ${ }^{8}$

Salah satu dampak yang terjadi akibat penambahan dan pengurangan wilayah adalah pergeseran batas garis pangkal (baseline) yang juga akan berubah. Baselines atau garis pantai sebagaimana diatur dalam Pasal 5 United Nations Convention on the Law of the Sea 1982 (UNCLOS 1982) adalah batas garis terluar suatu teritorial negara yang ditujukan untuk menjadi titik dasar dalam pengukuran batas laut kedaulatan negara dan zona maritim lainnya. ${ }^{9}$ Baselines menjadi sesuatu hal mendasar dalam delimitasi dan mengukur zona maritim bagi negara mengingat berdasarkan hal tersebut dapat melahirkan status hukum dari laut teritorial, hak lintas dan sumber daya alam yang dapat diakses atau dieksplorasi oleh negara. ${ }^{10}$ Sebagaimana Oppenheim menyatakan bahwa teritori merupakan hal yang sangat penting, karena tanpa wilayah teritori suatu kedaulatan tidak akan ada. Perubahan baselines akan sangat mempengaruhi negara pantai termasuk negara kepulauan, bahkan terdapat kemungkinan bahwa negara kepulauan tersebut akan kehilangan teritorial dan tidak dapat dihuni atau negara tersebut hilang sepenuhnya.

Pengaturan terhadap delimitasi merupakan hal yang diatur dalam Hukum Internasional karena meskipun negara dapat secara unilateral menyatakan baselines

\footnotetext{
${ }^{7}$ Stephen P. Leatherman \& Nancy Beller-Simms, 'Sea-Level Rise and Small Island States: An Overview' (1997) 24 Journal of Coastal Research, Special Issue.[2].

${ }^{8}$ S Taylor \& L. Kumar, 'Global Climate Change Impacts on Pacific Islands Terrestrial Biodiversity: a review' (2016) 9 Tropical Conservation Science.

${ }^{9}$ R. R. Churchill dan A. V. Lowe, The Law of The Sea 3rd Edition (Manchester University Press 1999).[31].

${ }^{10}$ E. D. Brown, The International Law of the Sea (Vol.I Introductory Manual) (Dartmouth Publishing Company Limited 1994).[20].
} 
atau zona maritim yang dimiliki diikuti dengan kondisi apabila tidak merugikan negara lain, mengingat keabsahan yang diambil tersebut berpengaruh terhadap negara lain yang memiliki zona maritim berdekatan. ${ }^{11}$ Resiko konflik yang rumit dapat muncul ketika dua negara bertetangga telah melakukan perjanjian terkait delimitasi di antara kedua negara tersebut, namun baselines yang telah diperjanjikan berpindah sebagai akibat dari kenaikan permukaan air laut. ${ }^{12}$

Selain melalui perjanjian antar negara tetangga, UNCLOS 1982 telah mengatur terkait baselines dan macam-macam baselines yang ada, namun belum terdapat ketentuan lebih lanjut ataupun pengaturan dalam hukum internasional yang mengikat mengenai kemungkinan perubahan baselines akibat kenaikan permukaan air laut oleh perubahan iklim. Walaupun terdapat pernyataan bahwa negara pantai dapat mengganti baselines yang telah hilang akibat kenaikan air laut menjadi baselines baru mengikuti kriteria yang tertera dalam Pasal 7 UNCLOS $1982,{ }^{13}$ pernyataan tersebut masih belum dapat dibuktikan secara nyata efektif dan tepat oleh negara-negara, mengingat apabila negara-negara menyesuaikan dengan baselines yang baru maka akan berdampak mengurangi zona maritim yang dimiliki dan hubungan-hubungan hukum yang lahir akibat tersebut.

\section{Rumusan Masalah}

Berdasarkan latar belakang diuraikan atas, maka penelitian ini akan fokus pada perumusan masalah sebagai berikut: Perubahan batas wilayah laut negara kepulauan akibat perubahan iklim menurut Hukum Internasional; dan Pengaturan penetapan baseline permanen terhadap negara kepulauan.

\section{Perubahan Batas Wilayah Negara atas Laut Akibat Perubahan Iklim}

Wilayah pantai merupakan simbol perantara antara lautan dan daratan yang

\footnotetext{
${ }^{11}$ Putusan Mahkamah Internasional, Fisheries (Inggris v. Norway) Judgment, 18 Desember 1951, I.C.J. Reports 116.[20]. (selanjutnya disingkat "Putusan Fisheries Case").

${ }^{12}$ A. H. A. Soons, 'The Effects of a Rising Sea Level on Maritime Limits and Boundaries' (1990) 37 Netherlands International Law Review.[219].

${ }^{13}$ ibid.[220].
} 
memiliki banyak manfaat yakni menjadi wadah kegiatan masyarakat. Wilayah pantai juga memegang peran penting dalam segi ekonomi dan bisnis seperti perdagangan, transportasi ekspor-impor, perikanan, pariwisata, industri, dan/ atau segi agricultural seperti pertanian, pertambakan dan lain-lain. Dalam hal tersebut, pemanfaatan wilayah pantai oleh masyarakat dalam suatu negara dapat menimbulkan beberapa macam akibat baik negatif dan positif. Semakin banyak keterlibatan manusia dalam mengeksploitasi sumber daya alam di wilayah pesisir pantai maka juga akan semakin terganggu keseimbangan dinamis mengingat pantai cenderung mengikuti bentuk profil dari perubahan aktivitas yang ada di tempat. Bilamana terjadi perubahan batas wilayah suatu negara, maka akan berdampak pada kedaulatan negara atas wilayah laut yang dimiliki, sebagaimana dengan bergesernya baseline maka berakibat berkurangnya suatu wilayah dan akan mempengaruhi hak berdaulat negara.

\section{Penetapan baseline berdasarkan UNCLOS 1982}

Berdasarkan Pasal 5 UNCLOS 1982, baseline adalah garis pangkal teritorial suatu negara yang ditujukan sebagai titik dasar dalam pengukuran batas laut kedaulatan negara dan. zona maritim lainnya. ${ }^{14}$ Baseline menjadi hal yang signifikan mengingat baseline merupakan komponen pondasi dari negara dalam menentukan yurisdiksi maritimnya, tanpa baseline negara tidak dapat mengukur batasan dari kedaulatan dan hak kedaulatan yang dimiliki. Baseline menjadi titik dasar untuk penghitungan luas laut teritorial, zona tambahan, zona ekonomi eksklusif dan landas kontinen, selain itu juga menjadi titik penentu atas batas wilayah zona maritim suatu negara dengan negara tetangga yang memiliki area maritim yang berdekatan atau bersinggungan. ${ }^{15}$ Sejalan dengan hal tersebut, baseline sangat perlu untuk ditentukan dan diatur secara tegas mengingat tidak semua negara pantai memiliki kondisi geografis yang setara, selain itu baseline juga digunakan untuk melindungi perairan pedalaman negara.

\footnotetext{
${ }^{14}$ R. R. Churchill dan A. V. Lowe, Op.Cit.[31].

15 Donald R. Rothwell, et.al., The Oxford Handbook of The Law of The Sea (Oxford Scholarly Authorities on International Law 2015).[69].
} 
Baseline dapat menjadi sumber dari sengketa antar negara mengingat dalam baseline diikuti kepentingan-kepentingan bagi negara pantai untuk memperluas wilayah kewenangan yang dimilikinya. ${ }^{16}$ Oleh karenanya, fungsi dari baseline selain sebagai titik dasar penentu laut teritorial suatu negara, baseline juga digunakan untuk penentu delimitasi batas maritim antar negara yang berdekatan. Baseline suatu negara harus digambarkan agar tidak ada pelanggaran atas pengaturan yang telah ditentukan, agar wilayah perairan yang secara dekat berhimpitan dengan wilayah daratan utama masuk kategori sebagai Perairan Pedalaman, dan agar menjadi pertimbangan apakah terdapat kepentingan-kepentingan seperti ekonomi atau lainnya atas suatu wilayah tertentu yang dapat dibuktikan melalui sejarah penggunaan yang berkelanjutan. ${ }^{17}$

\section{Archipelagic Baseline}

Archipelagic Baseline dibentuk sebagai wujud urgensi bagi negara kepulauan untuk mempertahankan yurisdiksi maritim yang secara kebiasaan telah menjadi bagian dari negara tersebut. Istilah tersebut lahir dari Indonesia melalui Deklarasi Djuanda yang menyatakan bahwa apabila komponen kepulauan Indonesia memiliki masing-masing laut teritorial yang terpisah, maka akan sangat sulit untuk melakukan peninjauan dan kontrol secara efektif sehingga sangat penting bagi negara kepulauan untuk mempertahankan kedaulatannya dengan Archipelagic Baseline tersebut. ${ }^{18}$ Archipelagic Baseline adalah baseline yang digunakan secara khusus oleh negara yang memiliki banyak kepulauan, seperti salah satunya Indonesia, Jepang, dan Filipina. Suatu negara dapat dikatakan sebagai negara kepulauan apabila kesatuan negara tersebut terdiri atas lebih dari satu kepulauan termasuk bagian dari daratan pulau yang besar yang mana kepulauan tersebut dihubungkan oleh perairan yang dekat. ${ }^{19}$

\footnotetext{
${ }^{16}$ ibid.

${ }^{17}$ R.R. Churchill dan A. V. Lowe, Op.Cit.[29].

${ }^{18}$ Fedelyn A. Santos, Beating the Deadline: Archipelagic State Compliance under UNCLOS Article 47 (Disertasi, World Maritime University Swedia 2008).[12].

${ }^{19}$ UNCLOS 1982, Pasal 46.
} 
Fungsi dari Archipelagic Baseline adalah untuk memberikan hak pada negara kepulauan dalam menarik garis batas laut dari satu pulau ke pulau lainnya, tetapi dengan tetap memperhatikan prinsip dari Freedom of Navigation sehingga negaranegara lain masih dapat melintasi perairan berdasarkan Hak Lintas Damai, ${ }^{20}$ dan Hak Lintas Alur Kepulauan. ${ }^{21}$ Selain itu, Archipelagic Baseline memiliki beberapa kondisi yang telah diatur dalam Pasal 47 (2) UNCLOS 1982 bahwa setiap panjang Archipelagic Baseline suatu negara terbatas pada 100 nautical miles (selanjutnya disebut "nm"), namun UNCLOS 1982 memberikan izin kepanjangan maksimum hingga $125 \mathrm{~nm}$ dengan jumlah syarat maksimal 3\% dari total keseluruhan titik Archipelagic Baseline yang telah ditetapkan. Penetapan Archipelagic Baseline tersebut juga dapat dilakukan pada low-tide elevations apabila terdapat instalasi permanen seperti mercusuar atau yang serupa dan/atau apabila letak low-tide elevations tidak lebih dari jarak laut teritorial pulau terdekat. ${ }^{22}$

\section{Laut Teritorial}

Laut Teritorial merupakan wilayah laut yang negara memiliki kedaulatan penuh baik secara yurisdiksi dan pengelolaan sumber daya alam yang terkandung di dalamnya. UNCLOS 1982 menyatakan bahwa setiap negara memiliki hak untuk menetapkan luas dari laut teritorial miliknya selama tidak melebihi batas maksimal yaitu $12 \mathrm{~nm}$ terhitung dari baselines yang telah ditetapkan. ${ }^{23}$ Penetapan batasan laut teritorial telah menjadi materi yang didiskusikan sejak 1930 dalam Konferensi Kodifikasi Hukum Internasional yang diadakan oleh League of Nations, pertemuan UNCLOS I dan II sehingga kemudian dinyatakan bahwa luas wilayah laut teritorial yakni sejauh $12 \mathrm{~nm}$, hal tersebut menjadi persetujuan internasional yang ditetapkan dalam pertemuan UNCLOS III. ${ }^{24}$ Laut teritorial menjadi hal yang esensial bagi

\footnotetext{
${ }^{20}$ ibid, Pasal 52.

${ }^{21}$ ibid, Pasal 53.

${ }^{22}$ ibid, Pasal 47 (4).

${ }^{23}$ ibid, Pasal 3 dan Pasal 4.

${ }^{24}$ Mazen Adi, 'The Application of The Law of The Sea and The Convention on The Mediterranean Sea', <https://www.un.org/depts/los/nippon/unnff_programme_home/fellows_ pages/fellows_papers/adi_0809_syria.pdf> accessed 30 November 2019.[17].
} 
negara yang memiliki wilayah laut. Dalam laut teritorial yang dimiliki, segala aktivitas menjadi hak negara secara absolut untuk digunakan.

\section{Perairan Kepulauan}

Perairan kepulauan merupakan perairan yang berada di sekitar wilayah negara kepulauan, sehingga perairan kepulauan adalah perairan yang ditutup dengan Archipelagic Baseline. Definisi dari perairan kepulauan tidak diatur secara tegas oleh UNCLOS 1982, oleh karena itu dalam penandatanganan perjanjian, Filipina menyatakan bahwa konsep dari perairan kepulauan di bawah UNCLOS 1982 adalah serupa dengan konsep Perairan Pedalaman dalam konstitusi Filipina. Adapun hal tersebut sangat ditentang oleh negara lainnya seperti Amerika Serikat dengan dalih bahwa perairan kepulaun tidak dapat disamakan dengan perairan pedalaman yang memiliki innocent passage dan archipelagic sea-lanes passage. ${ }^{25}$ Negara kepulauan memiliki kewajiban untuk mempublikasikan daftar atas koordinasi geografi negaranya ke Sekretariat Jenderal PBB sebagaimana diatur dalam Pasal 47 (9) UNCLOS 1982. Pendaftaran tersebut diwajibkan dan penting sebagai bentuk komunikasi atas klaim kepulauan kepada masyarakat internasional. ${ }^{26}$ Namun, perlu ditegaskan bahwa perairan kepulauan dengan perairan pedalaman adalah hal yang berbeda meskipun ditutup dengan baseline negara, yakni pada Hak Lintas Kapal Asing. Perairan Kepulauan memiliki beberapa rezim yang perairan pedalaman tidak miliki, seperti Innocent Passage, hak negara lain untuk menanam pipa atau kabel dalam dasar laut, dan lain-lain. ${ }^{27}$

\section{Perubahan Iklim}

Iklim adalah suatu hal yang mengacu pada rata-rata kondisi cuaca dalam jangka waktu tertentu yang penghitungannya terdiri dari temperatur, kelembaban

\footnotetext{
${ }^{25}$ Kevin Baumert dan Brian Melchior, 'The Practice of Archipelagic States: A Study of Studies.' (2015) 46 Ocean Development \& International Law.[71].

${ }^{26}$ ibid.

${ }^{27}$ Maria Maya L., 'Arti Penting Delimitasi Perairan Pedalaman Setiap Pulau di Indonesia' (2017) 25 Legality.[73].
} 
udara dan gerak angin. ${ }^{28}$ Pada dasarnya, iklim bersifat dinamis sehingga akan selalu ada perubahan dalam jangka waktu yang cukup lama, perubahan tersebut yang kemudian disebut sebagai perubahan iklim. ${ }^{29}$ Perubahan iklim mulai menjadi perhatian masyarakat internasional dan masuk dalam agenda politik internasional sejak awal tahun 1990 yaitu tahun 1992 pada Earth Summit yang kemudian lahir dan ditandatanganinya United Nations Framework Convention on Climate Change (“UNFCCC”). UNFCCC memiliki tujuan untuk menstabilkan konsentrasi gas yang dikeluarkan oleh rumah kaca sehingga menghindari gangguan antropogenik berbahaya terhadap sistem iklim. ${ }^{30}$ UNFCCC terbagi atas dua yaitu Annex I yang berisi terkait kewajiban bagi negara-negara maju untuk berkomitmen dalam mengurangi gas emisi, sedangkan dalam Annex II berkaitan dengan negara berkembang yang perlu mendapatkan bantuan dari negara maju untuk mengatasi efek dari perubahan iklim. Setelah UNFCCC, diikuti dengan terbentuknya Kyoto Protocol pada tahun 1997 oleh beberapa negara untuk mempertegas target dalam pengurangan emisi.

UNFCCC mendefinisikan perubahan iklim sebagai suatu perubahan dari iklim yang berkaitan secara langsung atau tidak langsung dengan aktivitas manusia yang mengubah komposisi dari atmosfer dunia dan merupakan varian iklimalami yang ditinjau dalam periode waktu yang secukupnya. ${ }^{31}$ Sedangkan menurut Badan Penerbangan dan Antariksa milik Amerika atau yang lebih dikenal dengan NASA (National Aeronautics and Space Administration), perubahan iklim merupakan fenomena global dalam jangkauan luas yang terbentuk terutama akibat pembakaran bahan bakar fosil sehingga menambah kadar gas penangkapan suhu panas oleh atmosfer bumi, fenomena tersebut berdampak pada kecenderungan meningkatnya suhu bumi yang dikenal dengan pemanasan global dan peristiwa pergantian cuaca ekstrim yang tidak menentu. ${ }^{32}$

\footnotetext{
${ }^{28}$ Joseph F. C. DiMento (Ed.), Climate Change: What It Means for Us, Our Children, and Our Grandchildren, (The MIT Press 2007).[13].

${ }^{29}$ Dr Md. Zulfequar Ahmad Khan, 'Climate Change: Cause \& Effect' (2012) 2 Journal of Environment and Earth Science.[48].

${ }^{30}$ United Nations, 'United Nations Framework Convention on Climate Change' (1992) vol. 1771 Pasal 2. United Nations, Treaty Series (selanjutnya disebut “UNFCCC”).

${ }^{31}$ UNFCCC, Pasal 1 (2).

${ }^{32}$ NASA, 'Climate Change: How Do We Know?'<https://climate.nasa.gov/evidence/>, accessed 27 November 2019.
} 
Perubahan iklim bukanlah hal yang dapat dirasakan dampaknya secara langsung oleh masyarakat sehingga agenda-agenda atau perjanjian internasional yang berkaitan dengan perubahan iklim masih tidak sebanding banyaknya dengan isu lainnya, selain itu diperlukan partisipasi yang aktif dari pemerintah negara masing-masing dalam mengimplementasikan perjanjian internasional terkait lingkungan atau berkaitan dengan pencegahan perubahan iklim. Selain itu, dampak dari perubahan iklim sangat dinamis sehingga beberapa negara mungkin merasakan dampak namun sisa negara lainnya tidak merasakan hal yang sama, oleh karena itu setiap negara memiliki sudut pandang berbeda atas perubahan iklim yang terjadi di wilayah mereka. Dengan terjadinya pemanasan global, penipisan lapisan ozon, penyusutan lapisan es, meningkatnya permukaan air laut, pengasaman dan semakin hangatnya air laut. ${ }^{33}$ Oleh karena itu, salah satu konsekuensi yang timbul akibat dampak dari perubahan iklim adalah perubahan wilayah negara atas laut.

\section{Pengaturan Penetapan Baseline Permanen terhadap Negara Kepulauans}

Pengaturan mengenai hukum laut dan delimitasi batas wilayah suatu negara atas laut diatur dalam satu kodifikasi pengaturan yakni pada UNCLOS. Secara keseluruhan pengaturan yang mengatur terkait delimitasi zona maritim dalam konvensi pada utamanya diatur dalam UNCLOS 1982 yakni pengukuran yang dilakukan melalui baseline. Namun, dalam UNCLOS 1982 tidak terdapat pengaturan lebih lanjut apabila terjadi perubahan batas wilayah suatu negara atas laut yang kemudian menimbulkan isu mengenai apakah baseline suatu negara mengikuti garis pantai atau apakah baseline yang pertama kali dinyatakan oleh negara menjadi baseline yang tetap atau permanen.

Apabila ditinjau berdasarkan elemen dari baseline itu sendiri berdasarkan Pasal 5 UNCLOS 1982 bahwa: 1. Titik Pangkal; 2. Diukur berdasarkan permukaan air terendah. Berdasarkan elemen yang tersedia, pengaturan dalam Pasal 5 UNCLOS 1982 menjadi hal yang dilematis dikarenakan perubahan

\footnotetext{
${ }^{33}$ Muhammad Ishaq-ur Rahman, 'Climate Change: A Theoretical Review' (2013) 11 Interdisciplinary Description of Complex Systems.[4].
} 
dari fenomena alam yang terjadi. Jika diterapkan secara harfiah, perubahan baseline sangat dimungkinkan untuk mengikuti garis pantai yang berubah akibat fenomena alam, selain itu, mengingat negara memiliki diskresi untuk menentukan dan menyatakan baseline sesuai dengan Chart Datum ${ }^{34}$ yang dimilikinya, maka secara teori, negara pantai dapat mengikuti dan menggunakan baseline baru sesuai dengan perubahan garis pantai akibat fenomena alam. Akan tetapi, perubahan tersebut menjadi cukup kontroversial mengingat terdapat dua kemungkinan perubahan wilayah yakni penambahan dan pengurangan. Selain dalam UNCLOS 1982, juga terdapat Resolusi Majelis Umum Perserikatan Bangsa-bangsa A/RES/44.206 (selanjutnya disebut "Resolusi Majelis Umum 44/206") sebagai bentuk kesadaran masyarakat internasional akan fenomena tersebut menunjukkan bahwa dampak dari fenomena alam di masa mendatang akan semakin memburuk dan menimbulkan potensi-potensi sengketa yang terjadi akibat dari kenaikan permukaan air laut.

Namun, mengingat bahwa pada hakikatnya Resolusi Majelis Umum tidak memiliki kekuatan hukum untuk mengikat negara, maka, dapat dikatakan bahwa Resolusi Majelis Umum 44/206 tersebut dibentuk sebagai wujud atas kepedulian masyarakat internasional, namun hingga saat ini belum ada pengaturan lebih lanjut mengenai hal yang berkaitan dengan penanganan negara-negara atas dampak perubahan iklim. Meskipun Resolusi Majelis Umum tidak memiliki kekuatan hukum yang mengikat, namun resolusi tersebut dapat menjadi unsur yang penting untuk mendirikan eksistensi dari hukum kebiasaan internasional atau untuk melahirkan suatu opinio juris, terutama Resolusi Majelis Umum 44/206 yang mengatur terkait penanganan akibat dari kenaikan permukaan air laut terhadap negara pantai, kepulauan dan/atau pulau yang surut.

\footnotetext{
${ }^{34}$ Chart Datum adalah bagan yang berisi rata-rata pengukuran permukaan air laut secara vertikal yang pada umumnya akan menghasilkan dua bentuk yakni positif ketika kenaikan air sedang pasang dan negatif ketika air sedang surut. Lihat: Nuno Sergio Marques Antunes, The Importance of The Tidal Datum in The Definition of Maritime Limits and Boundaries (International Boundaries Research Unit (IBRU) 2000).[4].
} 


\section{Implementasi Pengaturan Perubahan Baseline Negara Kepulauan}

Pengurangan wilayah negara atas laut merupakan hal yang tidak semua negara inginkan, mengingat akibat hal tersebut akan timbul isu yang dan konflik yang tidak dapat dihindari. Secara alami, negara tentu akan melindungi wilayah kedaulatannya atas laut baik untuk kepentingan politik, keamanan dan ekonomi sehingga kemungkinan bagi negara untuk memperbaharui baseline sesuai dengan garis pantai yang mundur adalah tidak memungkinkan. Peluang negara untuk kehilangan wilayah lautnya akibat fenomena alam lebih besar jika dibandingkan dengan penambahan mengingat isu perubahan iklim yang mengakibatkan kenaikan permukaan air laut dan erosi yang semakin memburuk.

Selain itu, dengan terjadinya kenaikan permukaan air laut, wilayah kedaulatan negara akan terganggu mengingat mundurnya garis pantai yang dimiliki negara, maka wilayah yang pada awalnya merupakan wilayah teritorial negara dapat berubah menjadi Zona Ekonomi Eksklusif yang mana negara tidak memiliki kedaulatan penuh melainkan hanya memiliki hak berdaulat (sovereign rights). Berkaitan dengan hal tersebut, dampak besar yang terjadi adalah pada negara kepulauan yakni negara kepulauan tersebut akan mengalami kerugian yang besar salah satunya adalah kemungkinan hilangnya status kepulauan yang dimiliki.

Fenomena kenaikan permukaan air laut dalam waktu kedepan dapat mengakibatkan hilangnya pulau kecil atau low-tide elevations karena eksistensi dari low-tide elevations sendiri adalah bergantung pada pasang-surut permukaan air laut, sehingga, apabila terjadi kenaikan permukaan air laut, low-tide elevations dapat tidak muncul kembali meskipun air sedang surut. Dalam putusan Maritime Delimitation and Territorial Questions between Qatar and Bahrain (2001) ditegaskan bahwa meskipun penggunaan low-tide elevations menjadi salah satu cara untuk menarik baseline dalam hukum kebiasaan internasional, akan tetapi hal tersebut tidak membenarkan asumsi umum bahwa low-tide elevations setara dengan pulau sendiri, ${ }^{35}$ kecuali dibangunnya instalasi permanen sebagaimana diatur dalam UNCLOS 1982. ${ }^{36}$

\footnotetext{
${ }^{35}$ Putusan Maritime Delimitation, Op.Cit., para 207.

${ }^{36}$ UNCLOS 1982, Pasal 7.
} 
Berkaitan dengan hal tersebut, bilamana low-tide elevations yang terletak dalam wilayah teritorial negara, maka, sesuai dengan Pasal 13(1) UNCLOS 1982 bahwa baseline tidak hanya diatur berdasarkan garis terluar dari laut teritorial namun juga merupakan baseline dari ZEE dan Landas Kontinen suatu negara, sehingga dengan hilangnya low-tide elevations juga dapat mengakibatkan berkurangnya zona-zona maritim negara. Hilangnya low-tide elevations secara garis besar tidak berdampak pada pengukuran dengan Straight Baseline dikarenakan Straight Baseline lebih tidak rentan perubahannya atas kenaikan permukaan air laut jika dibandingkan dengan Normal Baseline, hal tersebut dikarenakan penetapan Straight Baseline dari penarikan satu titik garis pantai ke titik lainnya. ${ }^{37}$

Berangkat dari penjabaran diatas, negara-negara yang akan berdampak secara signifikan akibat fenomena alam adalah negara kepulauan, seperti salah satunya Indonesia, Fiji, Filipina. Pengurangan wilayah akibat fenomena alam akan menjadi suatu permasalahan bagi negara kepulauan apabila salah satu pulau dari negara tersebut hilang atau tenggelam untuk selamanya. Negara kepulauan bahkan dapat terancam untuk kehilangan status negara kepulauan miliknya akibat kondisi negara tersebut tidak lagi memenuhi syarat negara untuk disebut negara kepulauan karena kemungkinan hilangnya pulau terluar yang menjadi basepoint untuk menarik archipelagic baseline. Berdasarkan hal tersebut, pulau atau wilayah negara yang tenggelam atau hilang akibat perubahan iklim maupun erosi, secara normatif, tidak memenuhi unsur pengukuran baseline berdasarkan UNCLOS 1982, sehingga diperlukan pengukuran baseline baru untuk garis pantai yang hilang akibat erosi atau perubahan iklim..$^{38}$ Namun, pada praktiknya, negara tentu akan menolak untuk melakukan pembaharuan baseline apabila terdapat wilayah laut miliknya berkurang atau hilang.

Pada dasarnya, baseline negara yang telah ditetapkan oleh negara dan kemudian didepositokan oleh negara kepada Sekretaris Jenderal PBB akan menjadi

\footnotetext{
${ }^{37}$ R. Lavalle, 'Not Quite a Sure Thing: The Maritime Arena of Rocks and Low-Tide Elevations Under the UN Law of the Sea Convention' (2004) 19 The International Journal of Marine and Coastal Law.[59].

${ }^{38}$ L. Alexander,'Baseline Delimitations and Maritime Boundaries' (1982) 23 Virginia Journal Of International Law.[535].
} 
permanen selama tidak ada perubahan yang diajukan oleh negara bersangkutan mengingat setiap negara memiliki kondisi geografis yang berbeda-beda sehingga penetapan baseline masing-masing negara tidaklah kaku. Apabila salah satu pulau menghilang atau menjadi karang yang tidak dapat dihuni, karang tersebut tetap menjadi titik basepoint selama tidak ada pembaharuan peta geografis dari negara kepulaun mengingat berdasarkan Pasal 76(9) UNCLOS 1982, suatu Archipelagic Baseline merupakan penetapan yang permanen setelah didaftarkan ke Sekretaris Jenderal PBB sehingga landas kontinen dari negara pantai tidak terkena dampak setelah garis pantai terluarnya telah ditetapkan. Pengecualian apabila salah satu pulau tenggelam dan hilang sepenuhnya, adapun secara teori, baseline negara tidak akan berubah selama telah didepositokan kepada Sekretaris Jenderal PBB.

\section{Kesimpulan}

Perubahan iklim merupakan fenomena alam yang terjadi secara evolusi. Dampak dari fenomena alam tersebut tidak langsung dapat dirasakan oleh negara, melainkan terjadi setelah melalui beberapa proses kompleks yang melibatkan baik lingkungan, iklim, dan aktivitas manusia. Salah satu dampak yang terjadi dari fenomena alam tersebut adalah pergeseran baseline negara yang berakibat pada perubahan wilayah negara atas laut.

Secara keseluruhan, pengaturan terkait pengukuran baseline dan zona maritim diatur dalam UNCLOS 1982, namun belum ada pengaturan secara spesifik atas perubahan baseline yang terjadi akibat fenomena alam. Sebagaimana dalam Pasal 16(2), 47(9), 75(2), 76(9) UNCLOS 1982, selama negara telah mendaftarkan baseline negara kepada Sekretaris Jenderal PBB, maka baseline yang didaftarkan berdasarkan diskresi negara tersebut merupakan baseline tetap. Mengingat negara memiliki kepentingan masing-masing dalam mempertahankan kedaulatan wilayah lautnya dan mengikuti kedinamisan dari perubahan garis pantai akibat fenomena alam, maka penetapan baseline secara permanen dapat menjadi solusi dibandingkan kemungkinan perubahan baseline mengikuti garis pantai, karena selain untuk kepastian hukum, terdapat juga potensi kerugian 
yang lebih besar terutama pada negara pantai dan negara kepulauan apabila tidak ditetapkan baseline secara permanen.

\section{Daftar Bacaan}

\section{Buku}

E. D. Brown, The International Law of the Sea (Vol.I Introductory Manual) (Dartmouth Publishing Company Limited, 1994).

Gemma Andreone, (Ed.), The Future of the Law of the Sea: Bridging Gaps Between National, Individual, and Common Interests. (Springer, 2017).

Joseph F. C. DiMento (Ed.), Climate Change: What It Means for Us, Our Children, and Our Grandchildren (The MIT Press, 2007)

Nuno Sergio Marques Antunes, The Importance of The Tidal Datum in The Definition of Maritime Limits and Boundaries (International Boundaries Research Unit, 2000)

R. R. Churchill dan A. V. Lowe, The Law of The Sea 3rd Edition (Manchester University Press, 1999).

\section{Jurnal}

A. H. A. Soons, 'The Effects of a Rising Sea Level on Maritime Limits and Boundaries' (1990) 37 Netherlands International Law Review.

Anny Cazenave, 'Global sea-level budget 1993-present' (2018) 10 Earth Syst. Sci. Data.

Dr Md. Zulfequar Ahmad Khan, 'Climate Change: Cause \& Effect' (2012) 2 Journal of Environment and Earth Science.

J. L. Chen, et.al. "Satellite Gravity Measurements Confirm Accelerated Melting of Greenland Ice Sheet.' (2006) 313 Science.

Kevin Baumert dan Brian Melchior, 'The Practice of Archipelagic States: A Study of Studies' (2015) 46 Ocean Development \& International Law.

L. Alexander, 'Baseline Delimitations and Maritime Boundaries' (1982) 23 Virginia Journal Of International Law.

Maria Maya L., 'Arti Penting Delimitasi Perairan Pedalaman Setiap Pulau di 
Indonesia.' (2017) 25 Legality.

Muhammad Ishaq-ur Rahman, 'Climate Change: A Theoretical Review' (2013) 11 Interdisciplinary Description of Complex Systems.

R. Lavalle, 'Not Quite a Sure Thing: The Maritime Arena of Rocks and LowTide Elevations Under the UN Law of the Sea Convention.' (2004) 19 The International Journal of Marine and Coastal Law.

\section{Perundang-undangan}

United Nations, Convention on the Law of the Sea, 10 December 1982, United Nations, Treaty Series 1833.

United Nations, United Nations Framework Convention on Climate Change, 9 Mei 1992, United Nations, Treaty Series, vol. 1771.

United Nations, Vienna Convention on the Law of Treaties, 23 May 1969, United Nations, Treaty Series 1155.

United Nations, Statute of the International Court of Justice, 18 April 1946, United Nations, Treaty Series 993.

UN General Assembly, United Nations Resolution / adopted by the General Assembly, 22 Desember 1989, A/RES/44.206.

Paris Agreement, 13 Desember 2015, dalam UNFCCC, COP Report No. 2, U.N. Doc. FCCC/CP/2015/10/Add, 1.

\section{Disertasi}

Fedelyn A. Santos, 'Beating the Deadline: Archipelagic State Compliance under UNCLOS Article 47.', (Disertasi pada World Maritime University, Swedia, 2008)

\section{Laman}

Agence-France Presse, 'Sea level rise from ocean warming underestimated, scientists say.', (The Guardian, 2016) <https://www.theguardian. com/environment/2016/jan/26/sea-level-rise-from-ocean-warmingunderestimated-scientists-say> accessed 19 Agustus 2019.

Mazen Adi, 'The Application of The Law of The Sea and The Convention on The Mediterranean Sea', <https://www.un.org/depts/los/nippon/unnff programme_home/fellows_pages/fellows_papers/adi_0809_syria.pdf > 
accessed 30 November 2019.

NASA, 'Climate Change: How Do We Know?', <https://climate.nasa.gov/evidence/ $>$ accessed 27 November 2019.

Pam Wright, 'Rising Seas Will Render Many Pacific Islands Uninhabitable by MidCentury, Study Says' (The Weather Channel 2018) <https://weather.com/ science/environment/news/2018-04-26-rising-seas-pacific-atoll-islandsuninhabitable-mid-century> accessed 19 Agustus 2019.

Tara Law, 'Record-Breaking Temperatures Around the World Are 'Almost Entirely' Due to Climate Change' (Time, 2019) <https://time.com/5652972/july-2019hottest-month/> accessed 8 Oktober 2019.

U.S. Department of Commerce, New Priorities for the 21st Century: NOAA Strategic Plan FY 2005 - FY 2010.' (NOAA, 2004) <http://oceanservice.noaa. gov/about/pdfs/noaa_strat_plan_2005_2010.pdf $>$ accessed 10 Desember 2019. 
Shofy Suma, dkk: Perubahan Baseline Negara...

--halaman ini sengaja dibiarkan kosong-- 